Portland State University

PDXScholar

\title{
Nurse Can't Even: the Immediate Impact of Incivility on Affect, Well-being, and Behavior
}

Katharine Lucille McMahon

Portland State University

Follow this and additional works at: https://pdxscholar.library.pdx.edu/open_access_etds

Part of the Psychology Commons

Let us know how access to this document benefits you.

\section{Recommended Citation}

McMahon, Katharine Lucille, "Nurse Can't Even: the Immediate Impact of Incivility on Affect, Well-being, and Behavior" (2020). Dissertations and Theses. Paper 5586.

https://doi.org/10.15760/etd.7458

This Thesis is brought to you for free and open access. It has been accepted for inclusion in Dissertations and Theses by an authorized administrator of PDXScholar. Please contact us if we can make this document more accessible: pdxscholar@pdx.edu. 
Nurse Can't Even:

The Immediate Impact of Incivility on Affect, Well-being, and Behavior

$$
\text { by }
$$

Katharine Lucille McMahon

A thesis submitted in partial fulfillment of the requirements for the degree of

\author{
Master of Science \\ in \\ Psychology
}

\author{
Thesis Committee: \\ Liu-Qin Yang, Chair \\ Tessa Dover \\ Charlotte Fritz
}

Portland State University

2020 
(C) 2020 Katharine Lucille McMahon 


\begin{abstract}
Interest in researching incivility has increased over the past two decades, as it is recognized as a pervasive issue in the workplace. Certain industries, such as healthcare, pose a higher risk for the aggressive encounters. Low intensity aggression, namely incivility, has a dangerous combination of high prevalence and invisibility that demands an understanding of the target's subsequent reaction process. Following rationale based on the Personality Systems Interaction (PSI) theory, this study proposes that the affective shift directly mediates the relationships between incivility exposure by coworkers and presumed behavioral and well-being outcomes at the day level in a daily diary design. A commonly observed outcome, strain, was operationalized by systolic blood pressure levels, offering an objective appraisal in contrast to the typical method of self-report. In addition, introducing procrastination as a novel behavioral outcome provides day-level cues for chronic outcomes such as work engagement. Based on theory and empirical evidence, this study contests that the capacity to regulate affect moderated by the availability of self-regulatory resources represented by the previous night's sleep quality, fully explains the relationship between incivility and its immediate outcomes, blood pressure and procrastination. Participants were 20 nurses from an organization located in the Boston metropolitan area. Results supported the relationship of incivility and affective shift with systolic blood pressure, but not procrastination. Furthermore, affective shift was not supported as a mediator for incivility's relationship with its outcomes. Implications, limitations, and future research directions will be discussed.
\end{abstract}




\section{Table of Contents}

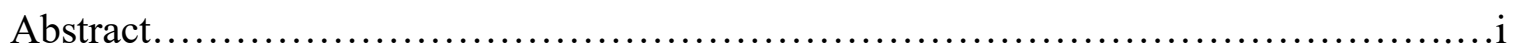

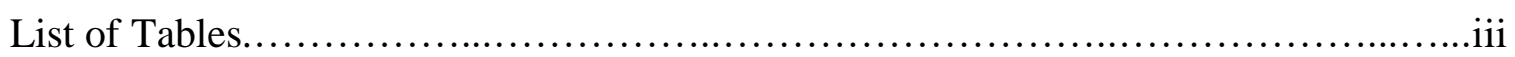

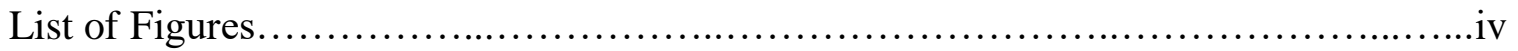

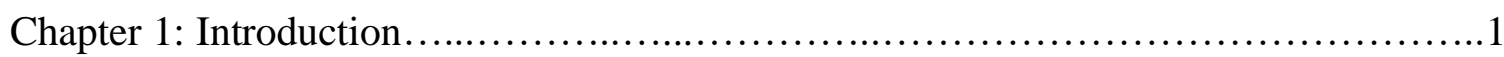

Chapter 2: Theory and Hypothesis Development................................... 7

Chapter 3: Methods............................................................... 17

Chapter 4: Results.....................................................24

Chapter 5: Discussion..................................................29

Tables........................................................................ 40

Figures............................................................... 47

References................................................................ 49

Appendix: All Scales...........................................................60 


\section{List of Tables}

Table 1: Means, Standard Deviations, and Correlations Between Focal Variables........40

Table 2: Multilevel Estimates for Model 1 Predicting Affective Shift.

Table 3: Multilevel Estimates for Model 2a Predicting Procrastination..................42

Table 4: Multilevel Estimates for Model 2b Predicting Residual Systolic Blood

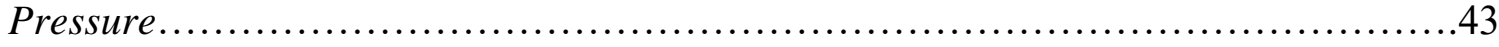

Table 5: Means, Standard Deviations, and Correlations Between Focal Variables......44

Table 6: Multilevel Estimates for Model 4 Moderating Effects of Sleep Quality...........44

Table 7: Research design and measurement time intervals for all focal variables and

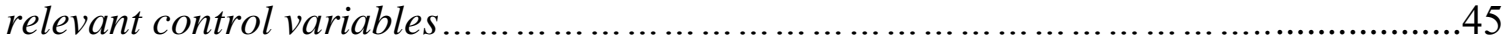

Table 8: Missing data for shifts and time points.................................46 


\section{List of Figures}

Figure 1: Affective Shift Model...............................................47

Figure 2: Hypothesized Conceptual Model.......................................48 


\section{Chapter 1: Introduction}

The ease in which an interaction can quickly have ambiguously rude components produces frequent uncivil encounters in the workplace. Incivility is defined as lowintensity, deviant behavior with ambiguous intent to harm (Andersson \& Pearson, 1999). Even this lowest form of aggression still results in negative consequences for the target individual and others (Schilpzand et al., 2016), and therefore warrants theoretical understanding of its insidious process.

In general, approximately $98 \%$ of U.S. workers experience incivility, with $50 \%$ experiencing it at least weekly (Porath \& Pearson, 2012). Furthermore, in the high-risk industry of healthcare, $85 \%$ of nurses reported experiencing incivility in the last year, with $37 \%$ admitting that they had instigated it (Lewis \& Malecha, 2011). The apprehensive and chaotic situations paired with the tense environment generates precarious characteristics that prime strained, agitated, and emotionally charged interactions. The various interactions with supervisors, staff, patients, and patients' families expose workers to daily uncivil acts (Lewis \& Malecha, 2011). Literature on incivility has repeatedly used the nursing population as their focus (Lewis \& Malecha, 2011; Oyeleye et al., 2013; Phillips et al., 2018; Spence Laschinger et al., 2009) due to the population's frequent exposure to it and therefore, this study also concentrated on nurses.

Unfortunately, nurses expect workplace aggression and consider it to be the norm. This normalization builds upon the already problematic inconspicuousness of incivility. Organizations can easily miss interpersonal conflict when it is ambiguous and low intensity, as the victim may not even deem the interaction rude until later reflection. In 
addition, as workplaces trend towards casual atmospheres, flattened hierarchies, and increasingly complex workplace interactions, available cues for defining proper, professional behavior diminish (Andersson \& Pearson, 1999). The ambiguity behind the classification of appropriate behavior complicates the decision to report or dissent, and facilitates the organization's blindness or passive non-reactions to the issue (Pearson \& Porath, 2005). Furthermore, the target needs to interpret the encounter as negative, which aggravates the ability to detect and curtail incivility from a third party. Managers can easily ignore these interactions to stay out of interpersonal conflicts if the victim does not overtly protest, or they can trivialize the significance of the conflict and regard them as personal matters (Pearson \& Porath, 2005). Worse yet, instances of organizations, or leaders, actually acknowledging the aggressive behaviors may ironically result in rewards to the perpetrators through perks, promotion, or favorable treatment (Hutchinson et al., 2010). The ease at which incivility can infiltrate a workplace enables ample consequences to unfold, although the progression to these outcomes remains inconclusive. Furthermore, nurses expect incivility from patients, but they also acknowledge that the culture tends to foster a lot of coworker incivility that may torment nurses more than aggressive acts from those they serve.

This present study focuses on daily occurrences of incivility among coworkers in nursing and attempts to identify the immediate progression of consequences that may provide insight to the development of attitudinal, behavioral, and well-being outcomes. Building upon a fairly new self-regulatory theory, the personality systems interaction (PSI) theory (Kuhl, 2000) and the corresponding affective shift model (Yang et al., 2016), the role of fluctuations in positive and negative affect provides a novel explanation 
for the link between incivility and the novel negative outcomes, procrastination and blood pressure. Besides suggesting a unique mediator, this study's extension on the PSI literature further clarifies the role affective shift patterns have for work outcomes during specific time intervals using a daily diary design. Furthermore, this study makes a new contribution to the affective shift literature by identifying a potential antecedent of affective shift that was alluded to but not yet tested by Yang and colleagues' (2016) affective shift model. Lastly, the inclusion of procrastination and blood pressure identifies outcomes that incivility literature has yet to explore.

\section{Known Consequences of Incivility}

Organizations should be concerned with, and discourage all forms of aggression, no matter how minimal, due to the various consequences affecting targets, witnesses, and the organization collectively. From a monetary standpoint, Lewis and Malecha (2011) calculated that productivity suffers by $20 \%$ in nursing and results in an annual loss of $\$ 11,581$ per nurse from incivility. Organizations should also be concerned that incivility has been linked with negative outcomes for targets and witnesses such as stress and withdrawal (Schilpzand et al., 2016). Therefore, incivility harms all employees and consequently the workplace climate. Furthermore, incivility correlates with attitudinal outcomes such as reduced motivation, effort, commitment, and dissatisfaction with work; behavioral outcomes such as counterproductive work behaviors, lower levels of task performance, and higher levels of withdrawal; and well-being outcomes, such as heightened emotionality, depression, anxiety, stress, changes in positive and negative affect, and lower levels of energy (Schilpzand et al., 2016).

\section{Attitudinal Outcomes}


Past research suggest that chronic incivility has strong negative associations with the work-related evaluations. For example, lower levels of satisfaction, such as job satisfaction, repetitively relate to higher levels of incivility (Cortina et al., 2001), including coworker incivility specifically (Miner et al., 2012). In addition, Caza and Cortina (2007) found that the perceptions of injustice and ostracism mediate incivility and institutional satisfaction. Some other attitudinal consequences such as work effort (Sakurai, 2011) and cognitive self-control (Rosen et al., 2016) indicate significant negative relationships with exposure to coworker incivility. Using an experience sampling method, Beattie \& Griffin (2014b) illustrated incivility relates to lower levels of work engagement, or the extent one is consumed in their work, at the day level. Multiple studies have also found incivility from coworkers, as well as other sources, to significantly relate to turnover intentions (Cortina et al., 2001; Oyeleye et al., 2013; Pearson \& Porath, 2005). On a more positive note, increased coworker civility (courteous and considerate behavior toward others) following an intervention leads to increased job satisfaction and managerial trust (Leiter et al., 2011).

\section{Behavioral Outcomes}

The potential negative impact of incivility also manifests as employee behaviors that depreciate the workplace. Work withdrawal through neglect or avoidance of work tasks becomes more prominent with higher levels of incivility from various sources (Cortina et al., 2001). Additionally, higher levels of absenteeism and turnover correspond with higher levels of incivility (Porath \& Pearson, 2012). High levels of coworker incivility also correlated to higher levels of counterproductive work behaviors such as theft, manipulating or disregarding work hours, or neglect of personal responsibility 
(Sakurai, 2011). Finally, coworker incivility may beget more incivility, as Rosen et al. (2016) found that experienced incivility predicted instigated incivility.

\section{Well-being Outcomes}

Various operationalizations of stress represent the most commonly measured well-being outcome. Miner et al. (2012) found that higher levels of workgroup incivility correlated to higher levels of stress and depression. Using depression and anxiety to represent daily and general stress, Beattie \& Griffin (2014b) observed that incivility positively relates to experienced stress. Cortina et al. (2001) also saw higher reports of distress in relation to higher reports of experienced incivility. Furthermore, higher levels of anger, fear, and sadness have been significantly linked to incivility (Porath \& Pearson, 2012). At the day level, end-of-work negative affect increased on days participants experienced uncivil encounters (Zhou et al., 2015). All of these studies included coworker incivility in addition to other sources (i.e. supervisor, general).

Although these studies have covered a breadth of consequences from incivility, a majority of them examine these relationships as cross-sectional and measure the outcomes at a single time point or level. Furthermore, only a select few examine mediation to explain the progression of these outcomes, which leaves a gap in the understanding of how seemingly inconsequential uncivil incidents manifest insidiously over time. Therefore, my research question is the following: Following incivility exposure, what is the reaction process that leads to negative outcomes? This study aims to examine if daily exposure of incivility has immediate outcomes on health and productivity, and to investigate if the affective shift mediates the relationship between 
incivility exposure and its immediate outcomes depending on the previous night's sleep quality. 


\section{Chapter 2: Theory and Hypothesis Development}

\section{Personality Systems Interactions (PSI) Theory and Affective Shift Model}

Kuhl (2000) proposed the Personality Systems Interaction (PSI) theory to

elucidate the interplay between affect and cognition to influence goal enactment and selfdevelopment. The theory emphasizes the independent processes of positive and negative affect. Shifts in positive affect dictate the initiation and pursuit, or regulation, of goals (Kuhl et al., 2006). An increase in positive affect facilitates the execution of goal-oriented actions, and a decrease in positive affect results in hesitation and thorough examination (Bledow et al., 2013; Kuhl \& Koole, 2008). A downward shift in positive affect will lead to analytical planning and deliberate intention, which will subsequently stall action and activity. A change in negative affect, however, influences the scope of attention for processing information. A downward shift in negative affect allows for holistic integration of pertinent memories to observe connections between stimuli and to achieve coherence between explicit goals and implicit needs, resulting in goals and actions aligning with one's responsibilities and duties. As negative affect increases, a person reacts with heightened alertness and absorption of specific information (Yang, Simon, Wang, \& Zheng, 2016). However, this heightened alertness can overwhelm an individual. The fluctuations for each affect correspond with fluctuations in cognitive mechanisms and attentional focus that subsequently dictate behavior. Therefore, changes in behavior from emotionally evoking events are embedded in a functioning system based on the interaction between affective and cognitive processes.

Bledow and colleagues built upon the PSI theory by proposing the idea of affective shift to illustrate the pairings of positive and negative affective shifts. In their 
empirical studies examining creativity and work engagement (Bledow et al., 2011, 2013), they developed the idea that the change in both dimensions of affect plays a distinct role in regulating work outcomes. They then compare the dynamic trajectories of both affects to one with only positive affective shift and a constant level of negative affect to elaborate on this idea. In their work, the primary focus was on the combination of upshift in positive affect and downshift in negative affect. Yang et al. (2016) then developed a model to present all possible combinations of change processes for positive and negative affect as seen in Figure 1. By placing positive affect on one axis to indicate cognition related to the goal-enactment and negative affect on the other axis to indicate cognition related to self-development, they identified the different quadrants representing the 4 combinations of upshifts or downshifts in each. They also empirically tested the Quadrants A and B, namely PA upshift—NA downshift and PA upshift-NA upshift. The focal shift for this paper is quadrant $\mathrm{C}$, or PA downshift—NA upshift.

An event such as incivility will most likely be followed by an increase in negative affect and a decrease in positive affect, and therefore, the subsequent cognitions should lead to behaviors that reflect a suspension in activity to thoroughly analyze the situation. Finally, this paper will focus specifically on coworker incivility. A recent meta-analysis of incivility by Hershcovis \& Barling, (2010) suggested that different sources may lead to different outcomes due to the relational aspect such as expected mutual respect from peers and that focusing on source will help decipher the nuances of reactions to workplace aggression. Indeed, recent studies have responded to the call finding value in understanding the role of coworker incivility (Demsky et al., 2019; J. G. Smith et al., 
2018; Verasari \& Hamzah, 2019). Reports suggest coworkers dominate as the most common source of incivility in nursing (Phillips et al., 2018).

\section{Hypotheses}

\section{Main Model}

Incivility exposure is inevitably negative, and therefore should be expected to evoke negative emotions and suppress positive ones. The PSI theory posits that the change in positive and negative affect influences information processing (Kuhl et al., 2006). The distressing event of incivility provokes directed reflection on the possibility of threat due to its ambiguous intent to harm. Incivility's deviant nature should prompt a strong association between its occurrence and negative affect regulation, to result in increases in negative affect in response to an uncivil event. The ambiguity of incivility may also cause an individual to consciously process their attitude toward the encounter in attempt to conclude if they feel attacked. On days an employee experiences incivility at work, they may contemplate different goals simultaneously while determining the ambiguous situation and avoid premature (re)action, which subsequently would lead to a decrease in positive affect (Kuhl et al., 2006). This supports the idea presented in the PSI theory that positive and negative affect are seen as separate regulation processes with different functions and change independently (Kuhl et al., 2006; Yang et al., 2016). This shift may be even more likely when the source of incivility is a coworker, as workers expect comradery, but acknowledge the commonality of mistreatment and poor behavior from patients.

Studies have repeatedly measured higher levels of negative affect as a proximal outcome of incivility (Giumetti et al., 2013; Porath \& Pearson, 2012; Sakurai, 2011; 
Zhou et al., 2015). In addition, it has been suggested that incivility may have a separate impact on positive affect (Cortina et al., 2001), however, this has been given less attention. Anxiety and depression, indicators of high negative affect and low positive affect, have followed incivility at the day level according to one study (Beattie \& Griffin, 2014). However, all of these past studies focused on the level of affect as opposed to the change, or shift, in affect. Incivility research would benefit theoretically and practically by knowing the extent and direction incivility relates to a shift in daily positive and negative affect. This would enable an understanding of the dynamic affect regulation following exposure to incivility. Furthermore, distinguishing the potentially different roles of positive and negative affect in response to incivility would extend the knowledge of the reaction process by inspecting the specific pairing of affective shifts.

H1: On days on which nurses experience incivility from coworkers during the first half of their shift, incivility will be related to PA downshift-NA upshift.

According to the PSI theory, a decrease in positive affect is associated with hesitation, thorough examination, analytical planning, and deliberate intention (Bledow et al., 2013; Kuhl \& Koole, 2008), that can, therefore, hinder action. Comparatively, an upshift in negative affect narrows attention to the immediate stimuli and details and impedes broader goal-oriented thinking. Following the PSI tenets on implications of affective shift as described above, with a decrease in positive affect due to an event such as incivility, an individual will fail to progress to enacting their goals or intentions; a simultaneous shift from low toward high negative affect upon incivility encounters will cause an individual to focus on details and inhibit broad thinking that would otherwise enable an individual to make connections between the immediate situation and their 
goals. Accordingly, the target will process the uncivil event and analyze the information thoroughly and overwhelmingly, failing to execute work-related intentions and goals leading to procrastination, an observable same-day outcome.

Empirical evidence suggests emotional reactions and changes in affect relate to behaviors reflecting work ethic and procrastination. Higher levels of negative affect relate to lower levels of work performance (Rothbard \& Wilk, 2011). Additionally, procrastination can serve as a mechanism for mood-repair when people are in a bad mood and anticipate being able to improve their mood (Tice et al., 2001). A longitudinal study, that also used the PSI theory to rationalize their hypotheses, found low positive affect mediated trait and state procrastination for both short and longer term tasks and that high negative affect from task-related frustration mediated long term tasks (Sirois \& Giguère, 2018). Given the low-intensity nature of incivility, shifts in affect (e.g. increased negative affect) may be perceived as easily malleable, and therefore reversible, so individuals may direct their attention to attempt to restore their original levels of affect (i.e. lower negative affect, higher positive affect) at the expense of work-related goals.

H2a: Experiencing PA downshift-NA upshift will be related to higher levels of procrastination later in the work shift.

Changes in affect should theoretically not only influence behavioral functioning, but physiological functioning as well. When a person becomes nervous, they may sweat. A frightened individual will feel their heart rate increase. When faced with an unpleasant stressful situation, such as incivility, which shifts an individual's positive and negative affect, it is reasonable to predict that these changes will also evoke bodily changes. Affective shift, specifically PA downshift — NA upshift, signals to an individual a threat 
exists, which in turn leads to strain. An individual's perception and interpretation of an event as being a threat, signaled by their affective responses, triggers physiological responses, known as allostasis (McEwen, 1998). This adaptive response can be taxing and result in allostatic load, or over activity of allostatic systems, such as blood pressure activity in the cardiovascular system. The trend of blood pressure can indicate chronic activation of a physiological system which indicates earlier stages of allostatic load (Ganster \& Rosen, 2013). Blood pressure elevation as a reaction to environmental stimuli may be extended if the stressor overwhelms an individual emotionally and they perceive it as a job strain (Landsbergis et al., 2013). Therefore, the individual may show a blood pressure trend that does not return to baseline within a reasonable amount of time, but continues to remain significantly above baseline, which adds to allostatic load (McEwen, 1998). Furthermore, in alignment with the PSI theory, PA downshift-NA upshift can prevent an individual from initiating action but instead ruminate on details and (over)analyze the situation, further distressing the individual and potentially adding to the allostatic load (Kuhl et al., 2006; McEwen, 1998). Affective shift strongly impacts the management of optimal personal functioning (Kuhl et al., 2006; Yang et al., 2016) and therefore should relate to physiological processes that indicate adaption to stressors, namely trend of blood pressure during the same work day.

H2b: Experiencing PA downshift-NA upshift will be related to higher levels of blood pressure later in the work shift compared to the same-day baseline.

The low-intensity yet powerful experience of incivility can be fleeting yet recurring, and therefore, the dynamic nature and subsequent reaction process should be explained by factors equally dynamic and continual. Thus, in agreement with Rosen et al. 
(2016), I contend that self-regulation, more specifically affective shift, dictates the reaction process.

Extensive literature has established that self-regulation oscillates depending on multiple factors and can be witnessed through affective, cognitive, behavioral, or physiological changes (Hagger et al., 2010). Furthermore, self-regulation closely relates to the regulation of both positive and negative affect (Diefendorff et al., 2000). Specific to affect-related outcomes following incivility exposure, researchers have identified higher levels of negative affect as a common, logical outcome of incivility exposure (Bunk \& Magley, 2013; Porath \& Pearson, 2012; Zhou et al., 2015). Additionally, it is important to note that the impact of incivility may be different for positive and negative affect (Cortina et al., 2001). This supports research that has trended towards distinguishing the two constructs as independent processes following incivility exposure, and therefore both positive and negative affective shift may play significant roles.

The PSI tenet posits that changes in level of emotion influence cognition and subsequent behavior due to affective shifts guiding information processing. Using affective shift as a mediator encompasses multiple dimensions of affect-regulation that inevitably interact (i.e. affect, cognition, attention, \& behavior). In accordance with the PSI theory, PA downshift-NA upshift should cause an individual to observe stimuli individually and meticulously analyze the information resulting in inaction and potentially "analysis paralysis" (Yang et al., 2016), leading to procrastination and strain. H3a: On days on which nurses experience coworker incivility during the first half of their shift, PA downshift - NA upshift will mediate the relationship between incivility and procrastination 
NURSES CAN'T EVEN

H3b: On days on which nurses experience coworker incivility during the first half of their shift, PA downshift-NA upshift will mediate the relationship between incivility and blood pressure

\section{Moderating Role of Sleep Quality}

Sleep consistently demonstrates strong connections to self-regulation, including its influence on emotion regulation (Palmer \& Alfano, 2017). Multiple studies examining sleep in relation to self-regulation have found that sleep quality, but not quantity, has significant influences (Barnes, Lucianetti, Bhave, \& Christian, 2015; Kühnel, Bledow, \& Feuerhahn, 2016), and therefore the current study only explores the role of sleep quality. Sleep quality has been repeatedly linked to depletion of resources hindering selfregulation and adaptive responses to stimuli (Barnes, 2012). In alignment with the strength model of self-regulation that views the ability to regulate as dependent on the amount of available resources, sleep has been identified as a necessary mechanism to restore these resources (Baumeister et al., 2000). Without sufficient resources, selfregulation processes such as affective responses, manifest more primitively as one does not have the energy to expend for more conscious self-control (Baumeister \& Vohs, 2016).

Furthermore, sleep interferes with the sensitivity and magnitude of emotions felt, such that studies have repeatedly demonstrated that sleep quality relates to higher levels of experienced negative affect and lowers levels of experienced positive affect (Berry \& Webb, 1983; Norlander et al., 2005; Scott \& Judge, 2006). From an evolutionary standpoint, negative emotions promote the prevention and minimization of harm by signaling potential threats while positive emotions prompt action tendencies to acquire 
social, physical, and psychological resources when feeling safe or secure (Fredrickson, 2001). Poor sleep may cause an imbalance in the experience of emotions, and therefore general affect, by intensifying negative affect and minimizing positive affect (Palmer \& Alfano, 2017) due to a consolidation bias associated with REM sleep (Kahn et al., 2013). As an adaptive function, this bias implies that weakened cognitive ability leads to selective encoding and prioritization of processing negatively valanced affective information, so threats become more salient and the encoding of positively valanced affective information diminishes as resource acquisition loses priority (Kahn et al., 2013). Thus, on days an individual has lower-quality sleep, they will 1) experience less positive affect, 2) are more likely to perceive something ambiguous, such as incivility, negatively and as a threat, and 3) consequently have a stronger negative and emotional reaction, as opposed to days the individual had higher-quality sleep. Furthermore, sleep deprivation can increase the vigilance and salience of threat-related stimuli in order to compensate for global impairment of cognitive performance and provoke sustained attention to the threat (Cote, Jancsar, \& Hunt, 2015; Palmer \& Alfano, 2017). Therefore, on days an individual experiences poor sleep quality the previous night, they may not only view incivility as a threat, but will ruminate and give it more attention than normal, which could enhance the affective reaction. One review on sleep and self-regulation in regard to the workplace summarizes the effects of poor sleep quality (and quantity) on cognitive and affective self-regulation, including attention deficit and inability to adjust moods adequately (Barnes, 2012). Adaptively, an individual will focus on negative cues as a priority and neglect positive cues with an inability to refocus and manage their levels of positive and negative affect effectively. Accordingly, I expect individuals to exaggerate the 
significance of the mild nature of incivility on days following lower-quality sleep and therefore, exacerbate the emotional reaction that follows.

H4: Sleep quality will moderate the relationship between incivility and affective shift, such that on days following poor sleep, the relationship between coworker incivility and PA downshift—NA upshift will be stronger. 


\section{Chapter 3: Method}

\section{Sample and procedure}

This study was conducted within a healthcare system in the Boston area. The organization comprised of multiple hospitals and clinics that serve the general population for care, research, and teaching. Although, all staff were encouraged to participate in the initial baseline survey, recruitment targeted nurses for their participation in both the baseline and the daily diary phase, the focus of this study. Researchers employed multiple methods to increase participants' willingness to participate, such as in-person interactions with participants, support from organizational management, publicizing the survey (through posters, announcements, etc.), and to establish the importance of the study as evidenced by the laboratory and field studies, including studies our team has conducted (Rogelberg \& Stanton, 2007; Yang, Johnson, Bauer, Groer, \& Salomon, 2014; Yang, Wipfli, Cyr, Currans, \& Wang, 2018). Additionally, the organizational management endorsed this study, encouraging the nurses to use their work time for their participation. This also helped enhance their willingness to complete all of the surveys. After initial advertisement of the study using the mentioned methods, the researcher visited the organization to increase awareness of the research study and also obtain feedback from nurses who had already agreed to participate. This feedback allowed for adapting the researcher's instructions email to clearly explain the daily diary phase with links to the surveys included. Weekly reminder emails also contained the links with a brief summary of the instructions and were sent out for approximately eight weeks.

The final sample for this particular study comprised of 20 nurses who were asked to complete daily diaries three times a day for six work shifts in two consecutive work 
weeks after completing a baseline survey about their demographics at least two weeks prior. Three nurses did not provide demographic information. The majority of nurses reported working day shifts, with two participants reported working evenings, one reported working nights, and one reported rotating shifts. Approximately half reported they work in ambulatory care and half in out-patient care. Twelve nurses worked in hospitals, mostly in intensive care units (ICU) or emergency departments (ED). The nurses were overwhelmingly female (i.e. one male participant was identified) with an average age of 50, ranging from 21 to 66 years old. The average job tenure was 20.24 years and the average organizational tenure was 16.69 years, both ranging from 3 months to 40 years.

Nurses received the necessary study materials and clear instructions for participation virtually (via email). Originally instructed to complete the six work shifts within a two-week time frame, less than half of the nurses did so. Results indicated that only 11 nurses completed six shifts or more (three people recorded seven shifts, one recorded eight shifts, and one recorded 13 shifts), and not always within a two-week time frame. We received a total number of 102 observations with valid data. Each observation theoretically comprised of three time points from the same work shift; nurses completed Time 1 surveys immediately after getting to work (T1), Time 2 surveys at the end of their meal break, approximately halfway through their shift (T2), and Time 3 surveys at the end of their shift (T3). At T1, T2, and T3 each shift, participants recorded their blood pressure during which they were instructed to sit still and measure twice for increased accuracy and with a two minute interval in between as done in previous research, using the average as the value (Eatough et al., 2016; Shockley \& Allen, 2013; van den Hoogen 
et al., 2000). Participants recorded their uncivil encounters at T2, affect at T1 and T2 (to assess shift within the same day), and reported prior-night sleep quality and same-day procrastination at $\mathrm{T} 1$ and $\mathrm{T} 3$, respectively. The separation of assessment scales across three surveys reduced the total time necessary to answer each survey (i.e., five minutes or less per survey), to help reduce participant fatigue and ensure response quality (Fisher $\&$ To, 2012) and minimized time taken away from their extremely busy schedule. Participants were briefed on the study procedures to abide by ethical concerns and maintain motivation to participate. Despite these efforts, of the 102 observations, 29 did not have information provided at $\mathrm{T} 2$ and 27 did not have information provided at T3. For a specific breakdown of the missingness of shifts and surveys see Table 8 .

\section{Measures}

All measures were chosen from the published literature. See the Appendix for all scale measures.

\section{Incivility}

Incivility research may benefit from focusing on a particular source and review of past studies indicates that internal sources have stronger effects than external (e.g. patients), and that repeated encounters inherent with coworkers may demonstrate more harm (Schiplzand et al, 2016). Therefore, we measured coworker incivility using the 5item Straightforward Incivility Scale (Leiter \& Day, 2013), which was adapted to ask about the particular time frame (i.e. during the first half of your shift) to establish directionality. The Likert-type scale ranged from 1 (never) to 6 (five times or more) (Leiter et al., 2015). A sample item was "During the first half of your shift, how often have your coworkers behaved in the following ways? Spoke rudely to you". Reliability 
for this study showed $\alpha=.78$ for the within-person level and $\alpha=.81$ for the betweenperson level.

\section{Affective shift}

Affective shift was measured by the change in positive and negative affect from Time 1 to Time 2. Positive and negative affect was each measured with 5 items from a shortened positive and negative affect schedule (PANAS) scale that has been validated in ESM studies (Thompson, 2007; Watson et al., 1988). Participants reported how they felt at that moment on a 6-point Likert scale ranging from 1 (not at all) to 6 (extremely). An example of a positive affect item was "inspired" and an example of a negative affect item was "upset". Reliability for positive affect at time 1 for this study showed $\alpha=.65$ for the within-person level and $\alpha=.95$ for the between-person level and $\alpha=.68$ for the withinperson level and $\alpha=.60$ for the between-person level for negative affect at time 1 . Time 2 reliabilities showed similar results as positive affect for the within-person level was $\alpha$ $=.82$ and $\alpha=.97$ for the between-person level, as negative affect showed $\alpha=.78$ for the within-person level and $\alpha=.82$ for the between-person level.

\section{Procrastination}

We measured day level procrastination with an adapted day-level version of Tuckman's (1991) procrastination scale with 6-items. Using a 5-point Likert scale format ranging from 1 (strongly disagree) to 5 (strongly agree), this has shown to be reliable in past ESM research (Kühnel et al., 2016). Sample items included “Today, I needlessly delayed finishing jobs, even when they're important". Reliability for this study showed $\alpha$ $=.73$ for the within-person level and $\alpha=.95$ for the between-person level.

\section{Blood Pressure}


The swift response of blood pressure to events makes it suitable for diary studies on incivility. In addition, blood pressure has already been established as a valid indicator of strain and predictor of prevalent health issues such as hypertension, especially among American workers (McEwen, 1998). Shockley and Allen (2013) observed change in blood pressure in reaction to work family conflict events to evaluate immediate levels in a daily diary. The participating organization provided nurses with the blood pressure monitors for this study. Furthermore, this study focused on systolic blood pressure due to past literature showing that systolic blood pressure produces more stable and reliable measurements of cardiovascular activity (Veit et al., 1997), especially for psychosocial stressors (Karlin et al., 2003). Furthermore, this study used blood pressure to indicate stress as a result of a threat and the subsequent affect. Stanton and colleagues used systolic blood pressure for convergent validity when developing the stress in general scale displaying the alignment between stress and systolic blood pressure (Stanton et al., 2001). Finally, one study has shown the mediational effect of negative affect specifically on systolic blood pressure (T. W. Smith et al., 2012). The accuracy of self-report should be sufficient as there is established agreement between self-reports and electronically stored assessments of blood pressure (Johnson et al., 1999). Additionally, the sample comprising of nurses, supported the argument to have them do it themselves due to their ample experience with the procedure.

\section{Sleep Quality}

Sleep quality was measured using the PROMIS scale with 8 items on a five-point Likert scale format ranging from 1 (not at all) to 5 (very much) with directions stating, "Please select the answer that best reflects your sleep from last night" (Yu et al., 2011). 
This scale was developed using the item response theory. An example item was "I had trouble sleeping"; however, one item, "My sleep quality was", had unique anchors, 1 (very poor) and 5 (very good), due to grammatical logistics (i.e. the anchors for the other items did not apply). The composite scores consisted of the raw sum of all items and then I transformed them into a T-score value to obtain standardized scores.

\section{Control Variables}

Beyond examining the relationships between the variables of interest, demographics such as gender, age, and tenure served as control variables. Previous studies have portrayed conflicting results for which gender is at greater risk for aggression (Campbell et al., 2011; Chen et al., 2009), and therefore, it was appropriate to control for potential gender differences. Due to nursing being a predominantly female occupation, it is possible that male nurses experience aggression differently from female nurses, and therefore have separate reactions. The demographic variables, age and tenure, have both been identified as risk factors for experiencing aggression in nursing (Campbell et al., 2011; Çelik et al., 2007; Kamchuchat et al., 2008; Pai \& Lee, 2011). Younger nurses have less experience, leaving them vulnerable to senior nurses as part of the "eat their young" culture and have less experience developing successful coping mechanisms.

Due to the inclusion of physiological measurements, it was necessary to minimize noise and alternative explanations for blood pressure levels by controlling for variables that impact its measurement. Past research has shown that caffeine, nicotine consumption, and medical conditions requiring accommodations that interact with blood pressure, such as prescription medicine or pacemakers, potentially influence blood 
pressure levels (Eatough et al., 2016; Gilbert-Ouimet et al., 2014). As such, these were also used as control variables.

\section{Power}

A review of ESM studies suggested that multiple time points increase statistical power for within-subject analyses, and multiple studies observing within-person mediation effects have had approximately 350 observations in total (with sample sizes of less than 100) (Ilies et al., 2016). Accordingly, this study has insufficient power to detect the proposed within-person mediational effects, due to the fact that the maximum amount of observations for a path was 102 . However, some paths were less given the fact that only 65 observations had blood pressure entries and only 76 had procrastination observations. This should be considered when assessing the conclusions later on. 


\section{Chapter 4: Results}

\section{Preliminary Analysis}

The first indices of importance for a multilevel model are the intraclass correlation coefficient (ICC(1)) that allowed me to examine the percent of variability that is explainable by daily fluctuations (vs. by participant individual differences). This indicated the appropriateness of multilevel modeling. Results showed support for analyzing the multilevel model as variance explained at day-level (i.e. 1 minus the ICC(1) value) in morning incivility (.72), affective shift (.81), blood pressure (.57), procrastination (.51), and sleep quality (.71) showed a large amount accounting for meaningful relationships between these variables at level 1. Furthermore, these ICC(1) indices suggested that there was a significant portion of between-person variance for these variables which needed to be taken into account when testing my within-personlevel research hypotheses. Therefore, to test my research hypotheses, I used linear mixed models (LMM) with fixed effect components by setting daily variables, like incivility exposure, at Level 1 and individual-level characteristics (e.g. age and tenure) at Level 2.

To test all hypotheses related to affective shift, we followed the best practice in prior literature (Bledow et al., 2013; Yang et al., 2016). Employing positive and negative affect measurements from time points 1 and 2, each affect levels at T2 was regressed onto the affect level at T1, respectively, to establish standardized residual change scores, which captured the $\mathrm{T} 2$ deviations from the expected value as predicted by $\mathrm{T} 1$ affect, and created two affective shift variables, one for positive affect and one for negative. Subsequently, I used the two change scores to create four continuous variables to represent pattern A: PA upshift-NA downshift, pattern B: PA upshift-NA upshift, pattern 
C: PA downshift-NA upshift, pattern D: PA downshift-NA downshift by summing the absolute value of the standardized residual scores to retrieve the value for the respective shift pattern with the three other variables having a value of zero (Yang et al., 2016; Yang et al., R\&R). For example, Pattern $\mathrm{C}$, the hypothesized combination of shift, showed a negative change score for positive affect and a positive change score for negative affect. Accordingly, identification of that pattern was then coded as the sum of the absolute value of those two residual scores to represent the extent of that shift and the other three patterns were coded as zero. This was done for each shift variable and the nonhypothesized shift patterns were then used as covariates.

Similarly, change in systolic blood pressure was operationalized by computing the standardized residual change scores by regressing the systolic blood pressure measure at $\mathrm{T} 2$ on $\mathrm{T} 1$. The reason for observing the change from Times 1 and 2 rather than Times 2 and 3 came from the logic that blood pressure reacts immediately to the surrounding environment or in this case the stressor, incivility, and would potentially return to baseline, after the stressor was no longer influential (i.e. before measurement at time 3; Wong \& Kelloway, 2016).

\section{Descriptive Statistics}

Calculations of the within person correlations between the focal variables, coworker incivility (first half of shift), PA downshift - NA upshift, sleep quality, procrastination, and systolic blood pressure, displayed expected relationships between most variables. Coworker incivility had a positive relationship with affective shift $(\mathrm{r}=$ $.03)$, and procrastination $(\mathrm{r}=.07)$, but had a negative relationship with sleep quality $(\mathrm{r}=-$

.12) and blood pressure $(\mathrm{r}=-.23)$. Affective shift had a negative relationship with sleep 
quality $(r=-.09)$ and procrastination $(r=-.02)$, but a positive relationship with blood pressure $(\mathrm{r}=.14)$. Sleep quality had a negative relationship with procrastination $(\mathrm{r}=-.11)$ and a positive relationship with blood pressure $(\mathrm{r}=.13)$. Finally, procrastination and blood pressure also had a positive relationship $(\mathrm{r}=.17)$. However, all relationships had a p-value greater than .05 and therefore, were non-significant.

All non-hypothesized combinations affective shifts demonstrated negative relationships with the focal affective shift at the within person level. Specifically the correlations were: PA upshift—NA downshift $\mathrm{r}=-.08(\mathrm{p}>.05)$; PA upshift-NA upshift $\mathrm{r}=-.11(\mathrm{p}>.05) ;$ PA downshift—NA downshift shift $\mathrm{r}=-.13(\mathrm{p}>.05)$.

\section{Hypothesis Testing}

I conducted analyses for hypothesis testing using the software program Mplus (version 7.2; Muthén \& Muthén, 1998-2014). Day level variables such as the focal variables of the model were set as level one and person, or trait, level variables were set as level two. In order to account for between person variance, the level-1 predictor (coworker incivility), mediator (affective shift), and moderator (sleep quality) were person-mean centered. Gender, age, job tenure, and organizational tenure represented covariates in all analyses as did medication, nicotine, and caffeine consumption for blood pressure analyses. All models were tested using maximum likelihood estimation with fixed effects for two reasons: First, between-person random variances of focal relationships (e.g., the incivility-affective shift relationship) were statistical nonsignificant in the random-effect models; second, using a fixed effect model allows for higher statistical power (Beal, 2015). 
Hypothesis 1 stated that on days on which nurses experienced incivility, they will also experience PA downshift—NA upshift. A baseline multilevel model regressed PA downshift - NA upshift on coworker incivility at level 1 to test this hypothesis while controlling for age, gender, job, and organizational tenure. Results showed a significant relationship between coworker incivility and this particular affective shift, $B=.03, S E$ $=.01, \mathrm{p}<.02$, and therefore showed support for Hypothesis 1. Age also showed a significant negative relationship in predicting affective shift.

Hypothesis 2 stated that experiencing PA downshift-NA upshift will relate to higher levels of a) procrastination and b) blood pressure. From the fixed effects model for procrastination, results indicated a nonsignificant relationship with affective shift, $B=$ $.01, S E=.13$, ns. Therefore, Hypothesis 2 a was not supported. Job tenure showed a significant negative relationship and organizational tenure showed a significant positive relationship with procrastination. Interestingly, PA upshift-NA upshift, also showed a significant relationship with procrastination, $B=.21, S E=.06, \mathrm{p}<.001$.

Alternatively, for the blood pressure model, results did show a significant, positive relationship with affective shift, $B=.53, S E=.25, \mathrm{p}=.03$. These results demonstrated that PA downshift-NA upshift relate to a significant change in blood pressure levels showing support for Hypothesis $2 \mathrm{~b}$. Additionally, caffeine consumption at both time 1 and time 2 showed significant positive relationships with change in systolic blood pressure, verifying an established relationship between them.

Hypothesis 3 proposed that on days nurses experience incivility, they will report higher levels of a) procrastination and b) blood pressure mediated PA downshift-NA upshift. Even though Hypothesis 2a was not supported, analyses were conducted for the 
purpose of this project. Unsurprisingly, results displayed that affective shift does not mediate the relationship between incivility and procrastination with an essentially nonexistent indirect relationship $B=.00, S E=.00$, ns. Alternatively, results from a fixed effects mediation model for blood pressure showed nonsignificant results $B=.01, S E=$ .05 , ns. Therefore, Hypothesis $3 \mathrm{~b}$ was not supported. Furthermore, caffeine consumption at time 2, once again, showed a significant positive relationship with systolic blood pressure change, while consumption at time 1 showed marginally significant results.

Finally, Hypothesis 4 examined the role of sleep quality in the relationship between incivility and affective shift. It proposed that the relationship would be strengthened on days following poor sleep. Results from a fixed effects model indicated this trend theoretically, but ultimately showed that sleep quality does not play a significant role with values of $B=-.01, S E=.12$, ns. As for control variables, age displayed a significant negative relationship with affective shift and organizational tenure had a marginally significant negative relationship with it. 


\section{Chapter 5: Discussion}

Results from this study suggested that incivility and affective shift may predict systolic blood pressure level but not procrastination. Furthermore, incivility's association with blood pressure was not mediated through affective shift, suggesting that incivility and affective shift have distinct, separate roles in physiological reactions. Although incivility predicted affective shift, there was no evidence that the same path continues on to blood pressure. Additionally, the previous night's sleep quality did not appear to moderate this relationship between incivility and affective shift. All hypotheses involving procrastination did not show support for it as an outcome from either incivility or affective shift. Next, I will provide theoretical and methodological explanations for why the results occurred.

\section{Implications}

Results suggested that incivility experienced during the first half of a nurse's shift predicted PA downshift-NA upshift. Past literature has provided related evidence, especially in regard to levels of negative affect as ESM designs have produced results with higher levels of negative affect following incivility (Park et al., 2018; Sakurai, 2011; Zhou et al., 2015). This study builds upon the research by also including positive affect, something addressed less often but still had theoretical support for incivility's differential impact on positive and negative affect (Cortina et al., 2001). This study expands on the idea and looked at the pairing of both affective shifts as one unit. Furthermore, this study expands upon previous research by establishing the actual shift of affective states rather than the levels, and by focusing on shift in both positive and negative affect. This provides insight to the PSI theory and the affective shift model that argues for the 
dynamic component of emotions as pivotal in the influence for cognitive and motivational processes such as attention and goal orientation (Kuhl et al., 2006; Yang et al., 2016).

The nature of nursing may explain the null results for a relationship between PA downshift - NA upshift and procrastination. The job entails tasks that require immediate attention due to the fact that nurses see and treat patients in the moment and any delay may have serious, even fatal, consequences. This is especially true when considering that the majority of participants worked in emergency departments. The PSI theory posits that the PA downshift-NA upshift should lead to an interruption in action towards goals as one thoroughly analyzes their situation, rather than taking action, and also focuses on small details or immediate needs of threatening deadlines (Kuhl \& Koole, 2008; Yang et al., 2016). Serious health issues dictate the priority of tasks and their "deadlines" due to the fact that delay may result in permanent health damage. Therefore, specific goals consist of these imperative actions, usually requiring attention before a shift ends. The alertness that accompanies an NA upshift may encourage nurses to focus and complete their specific tasks with imminent deadlines, and subsequently, they tend to report less procrastination during the pertinent shift.

Furthermore, the fact that a PA upshift-NA upshift predicted more procrastination may provide additional insight on factors that delay the accomplishment of tasks. In this case, alertness from an NA upshift will still draw attention to smaller details and immediate concerns, but when accompanied with a PA upshift, the effect of heightened attention does not necessarily result in accomplishing all tasks. A PA upshift prompts the motor control system to act based on intuitive information processing (Kuhl, 
2000) so that nurses may not respond by addressing designated work goals but instead react to their surrounding environment (i.e. patients in need of care). This intuitive reaction may hinder accomplishment of less pressing tasks, such as paperwork, leading them to report delayed tasks that shift.

In contrast, Yang et al. (2016) found that PA upshift-NA upshift was associated with higher self-reported task performance among high-tech workers. However, as previously mentioned, the tasks in nursing require a specific approach for prioritizing. The difference in industries and how work goals function may explain the difference due to the fact that heightened attention in a hospital, especially an emergency setting, directs attention differently than in an office setting. Furthermore, Yang et al. (2016) measured task performance with a single item "Today, I performed my job well", indicating a divergence between the task performance and procrastination constructs, as it is possible for an employee to believe that they did a good job, but may not have completed their entire task list for the shift. This could be especially true for nurses when considering their inclination to accomplish immediate patient care tasks but surrender less critical concerns (i.e. paperwork) during a shift. Finally, seasoned nurses may be able to control their attention, be less impacted by the aforementioned PA upshift and NA upshift processes, and maintain their overall work goals better when experiencing affective shifts from years of developing coping skills, thereby explaining the significant negative relationship between job tenure and procrastination.

In contrast, results showed affective shift was linked to blood pressure.. Theoretically, this relationship should occur, due to the fact that people have less control over natural physiological reactions so that even with experience or coping skills, the 
body still reacts when faced with a threat (McEwen, 1998). Therefore, even though nurses may not allow change in affect to influence them externally (i.e. behaviorally), they have less control internally. From an evolutionary perspective, an increase in negative affect and a decrease in positive affect signals to a person that something potentially endangers their well-being, resulting in reactions to the primary systems of the body, known as primary mediators such as stress hormones (e.g., epinephrine, norepinephrine, and cortisol; Ganster \& Rosen, 2013). In the allostatic load model, which illustrates the physiological basis of stress, the persistent activation of primary mediators leads to secondary outcomes, including blood pressure (Ganster \& Rosen, 2013).

The third hypothesis focused on the mediational path of affective shift in the relationships between incivility and the outcomes-procrastination and blood pressure. For both cases, null results implied PA downshift—NA upshift does not mediate the relationship between coworker incivility and procrastination nor systolic blood pressure. Due to the fact that procrastination as an outcome displayed null results overall, this is unsurprising, especially when considering the explanations above. Other arguments may suggest an alternative mediator such as rumination. The PSI theory and the affective shift model posit that lower positive affect results in planning and analyzing for goal enactment, however, abundant low positive affect may lead to overthinking and extensive consideration of the situation (Kuhl \& Koole, 2008) or analysis paralysis (Yang et al., 2016). Therefore, rumination may be caused by the ambiguity of incivility as an individual ponders the experience and considers the different aspects of the situation in order to form a conclusion about a potential threat. That is, rumination can be a mediator alternative to affective shift in the relationships of incivility with procrastination and 
blood pressure. Thus, it may be fruitful for future research to examine affective shift and rumination as dual mediators in the incivility- procrastination and incivility-blood pressure relationships.

However, with blood pressure as an outcome each separate path of the mediation showed significant results, as incivility significantly predicted a larger extent of PA downshift — NA upshift and PA downshift—NA upshift significantly predicted positive residual changes in systolic blood pressure. The fact that a mediational path was not confirmed may be due to the low power of this study. Low power increases the chance of a Type II error, or false rejection of a true null hypothesis. Similarly, the null results regarding the final hypothesis of sleep quality's role in the relationship between incivility and affective shift may be due to the sample size and lack of power to detect moderation. Researchers acknowledge the notorious difficulty in detecting interactions in multi regression analyses with continuous variables (Shieh, 2009).

\section{Theoretical Contributions}

First, the proposed study aimed to provide evidence for affective shift as a form of self-regulation that mediates the relationships between daily incivility exposure and immediate outcomes. Although past studies have implied mediators for the incivilityoutcome relationships, extensive evidence still remains dormant. For example, multiple cross-sectional studies suggest mediation by injustice and ostracism (Caza \& Cortina, 2007), cognitive appraisals (optimism), emotional responses (emotionality) (Bunk \& Magley, 2013), and levels of negative emotions (Sakurai, 2011). Rosen et al. (2016) provided an initial demonstration of self-regulation explaining the immediate reaction process following incivility by operationalizing self-control as a cognitive construct in an 
ESM study. The current study encompassed state affective measures of self-regulation to examine its role in the mediation process. Using affective shift, I consolidated the literature by viewing self-regulation as a multi-faceted mechanism with automatic affective and cognitive processes that theoretically influence behaviors and physiological reactions dependent on self-regulatory resources available. Furthermore, the fluidity of affective shift conscientiously reflects the daily fluctuations of immediate outcomes following incivility.

Similarly, a second contribution of the present study concerns the extended understanding of PSI theory and specifically, expansion of the affective shift model and research by examining a theoretically relevant antecedent of affective shift and testing an unexplored affective shift pattern (PA downshift—NA upshift). A fairly new theory, PSI theory incorporates the complex, dynamic interaction between positive and negative affect and cognition to explain well-being and behavior (Kuhl, 2000; Kuhl et al., 2006). This aspect of PSI positions it perfectly as a central theoretical framework to explain the relationships of incivility with strain (well-being) and procrastination (behavior). The affective shift model emphasizes the significance of observing behavior as a result of dynamic affective regulation (Bledow et al., 2013; Yang et al., 2016). As previously mentioned, self-regulation as a mediator for daily fluctuations in incivility has been supported, but limited to the cognitive aspect (Rosen et al., 2016). Affective shift influences goal enactment through the regulation of positive affect and influences selfdevelopment through the regulation of negative affect, which then instigates an individual's subsequent behavior (Kuhl et al., 2006). Consequently, the role of affective shift in regulation processes has promising implications that have yet to be fully 
investigated. Our study adds to the relative small yet growing body of literature testing PSI theory, and the affective shift model that has focused on the dynamic nature and shift of emotions (Bledow et al., 2013, 2011; Yang et al., 2016).

A third contribution entails the physiological measurement of strain as an outcome. One of the most researched outcomes of incivility is stress, or more accurately stated when referring to the outcome of the stress process, strain. Most of this research utilized some form of self-report measures such as the use of the Mental Health Index (Cortina et al., 2001), Stress in General scale (Miner et al., 2012), Perceived Stress scale (Oyeleye et al., 2013), or the Depression Anxiety Stress scale (Beattie \& Griffin, 2014). The present study adds to the literature of incivility and strain by offering an objective measurement of strain via systolic blood pressure readings, to provide physiological evidence and strengthen the validity of the incivility-strain association. In particular, this study focused on trends in levels of blood pressure to reflect fluctuations in strain rather than simply levels of strain.

\section{Limitations and Directions for Future Research}

A severe limitation to this study is the sample size and subsequent lack of statistical power. The majority of hypothesis testing resulted in having a cluster of 17 (i.e. 17 participants) and approximately 70 observations. As previously discussed, a literature review of ESM studies observing mediational effects suggested that studies with around 350 observations provides sufficient power to detect the effects (Ilies et al., 2016). In

general, a small sample size and lack of power increases the chance of a Type II error, or false negatives, so that the relationships among variables remains undetected, especially 
variables with small effect sizes, a typical characteristic of psychological constructs. This could further explain why blood pressure, a physiological construct, displayed significant findings. Therefore, this study's lack of observations may explain the reason for null results, particularly those relating to hypothesis 3 (i.e. mediation). Furthermore, moderation also requires a larger sample size and is more sensitive to statistical power, also providing reason behind the inconclusive results.

Another limitation focuses on the range of answers provided for incivility and procrastination. First, the base-rates of both variables are low at the day-level as coworker incivility had an average of 1.05 with a maximum of 1.65 and a standard deviation of .15 , and similarly, procrastination showed an average of 1.37 with a maximum of 2.50 and a standard deviation of .43 , both on a scale of one to five. This displays not only low frequency of behaviors at the day level, but also a range restriction resulting in smaller variance and lack of power. These results contradict much of the incivility research in nursing that shows evidence for its prevalence in healthcare (Schilpzand et al., 2016). These low values could be a result of the examination of the day-level, a shorter time frame, and the fact that nurses only reported incivility that occurred during the first half of their shift. It is possible that as the shift progresses fatigue begins and more interactions transpire, more incivility will appear. Future research could investigate the probability of incivility based on varying intervals within a shift (e.g., using half of shift, two third of a shift, full shift) to establish specificity of when nurses might expect to encounter aggressive coworkers, and to possibly increase the variability of the incivility measure and statistical power for hypothesis testing. 
Additionally, as with much of workplace surveys, this study relies mostly on single source, self-report to measure the variables of interest, incivility, affective shift, sleep quality, and procrastination, due to feasibility. This leads to issues of common method variance (CMV), influencing the relationships between variables (Podsakoff et al., 2003). However, Podsakoff et al. (2003) suggest that different measurement time points for variables diminish this issue. The variables affect, incivility, procrastination, and sleep quality were measured at separate times in the day with minimal overlap, in order to minimize CMV. Future research could improve upon this further by using multisource or objective measures. For instance, perpetrators and witnesses could report incivility in addition to the target, and actual time and work produced contrasted with timeline and work output expectations could represent procrastination.

Employing objective measures of strain did not completely solve internal validity concerns. This study measured strain objectively with blood pressure, but blood pressure measurements have their own uncertainties, providing another limitation. A lot of factors can create confounding variables that influence blood pressure recordings and levels. Although, the most common influences were accounted for (i.e. caffeine consumption, nicotine consumptions, and medical needs), random errors in conducting momentary blood pressure measurements may bias the recordings. Furthermore, nurses, particularly in emergency departments, face stressors continually, and an unmeasured environmental factor may cause heightened levels. Although nurses minimally reported adverse or major events in their reports. A total of six nurses all reported a single event happened during one of their shifts, with the exception of one nurse who reported "a large volume of patients. Many with high acuity", meaning they had significant yet unpredictable needs. 
The causal conclusions that can be drawn from this study are also limited, even with an ESM design. Despite having multiple time points to establish directionality, I cannot make causal inference confidently. The use of an observational field study enhances external validity at the cost of internal validity and sufficient control, which undermines confidence for inferences. Therefore, future research may wish to increase control using an experimental design, so that directionality can be established, and alternative explanations can be inhibited.

Finally, the study sample was obtained by convenience sampling using personal networks to recruit participants. This method of sampling may lead to biases that hinder generalizability. It is possible the sample of nurses is not representative of the population of nurses and may be restricted by factors such as location or purpose of the organization (e.g. public vs private, community-oriented), or even department (i.e. mostly emergency settings). This particular organization aims to serve the surrounding community, and more specifically, low-income citizens, which may distort the expectations and norms of the environment, and subsequently influencing the relationships between variables.

Future research could build upon this model to examine contingency factors, such as social support, which may increase the capacity to self-regulate and buffer the connection between incivility and its consequences. For example, prior research has found evidence for the benefits of aggression preventive supervisor behaviors (APSB) on deterring workplace aggression toward healthcare workers (Yang \& Caughlin, 2017). APSB is defined as supervisor behaviors that directly or indirectly help prevent employees from exposure to aggression (Yang \& Caughlin, 2017). Our research team has also developed a pilot intervention program in which line supervisors in healthcare can be 
trained to enact more frequent APSB in effort to reduce and prevent their employees' exposure to aggression from patients and co-workers, as well as promote workers' health and safety. Future research may examine how APSB in general, or at the day level, may buffer the negative effects of daily incivility exposure and/or reduce occurrence of daily incivility. Future research could explore alternative mediation mechanisms to explain the connection between incivility and its outcomes. As previously mentioned, one alternative is rumination. The ambiguity of incivility and subtle characteristic may lead a nurse to consider the interaction before having a reaction, emotionally, behaviorally, or physiologically.

\section{Conclusion}

In summary, this study provides evidence that incivility does relate to immediate emotional shifts, specifically, PA downshift—NA upshift. This aligns with past studies and theoretical reasoning based on the consequences when exposed to threats. Additionally, these types of changes in emotion also predicted higher levels of blood pressure. However, conclusions cannot be drawn about the relation of incivility and affective shift with productivity, namely procrastination. This may be a result of the context and time frame in which the study was conducted. Furthermore, these finding do not provide support for the role of sleep quality in the relationship between a threat such as incivility and the subsequent emotional reaction. This relationship possibly remained undetected due to a small number of observations and resulting low statistical power. In a occupation such as nursing where incivility occurs ubiquitously, it is important to continue to inspect exposure to incivility and its immediate impact on the daily lives of workers who endure ample amounts of stressors. 
Tables

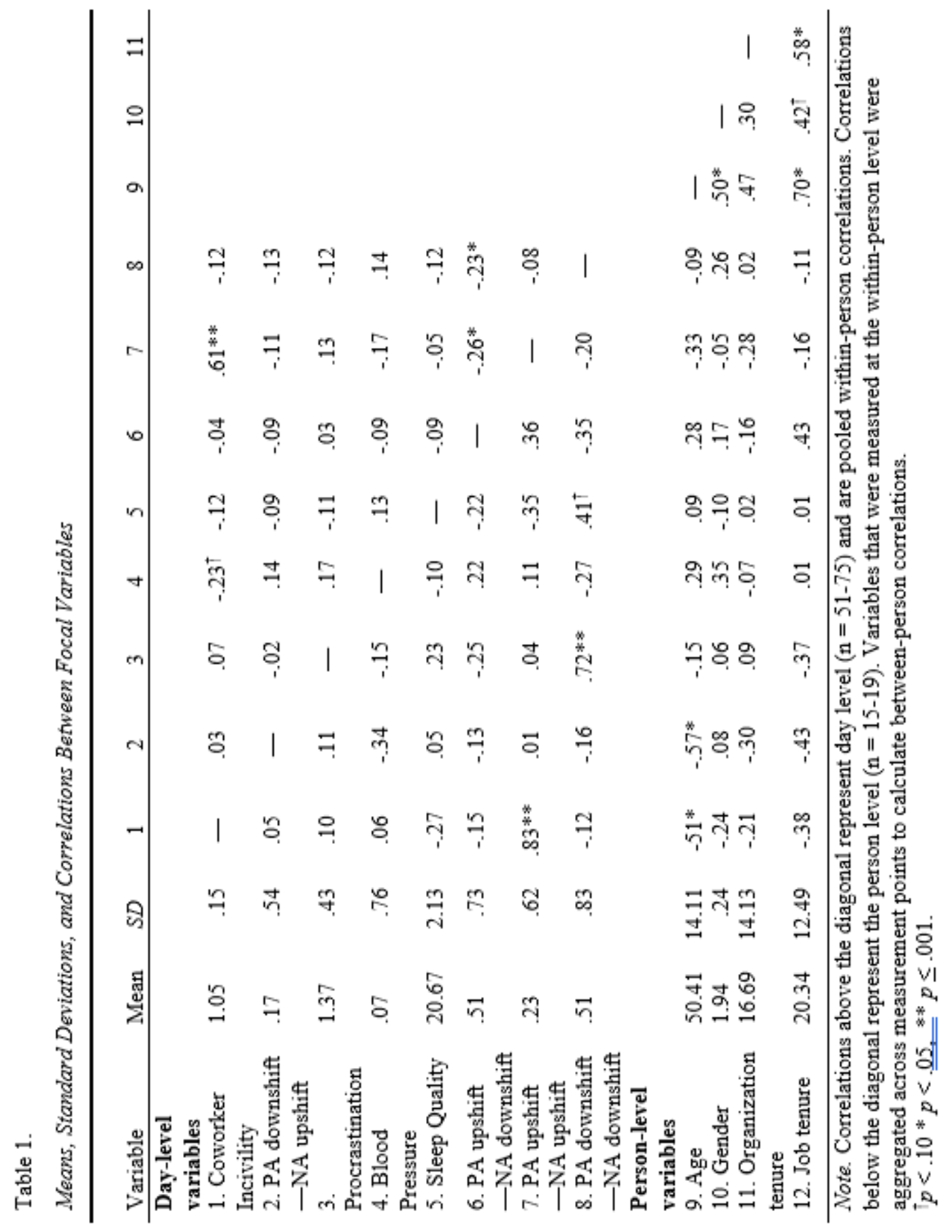


NURSES CAN'T EVEN

Table 2.

Multilevel Estimates for Model 1 Predicting Affective Shift

PA downshift—NA upshift

Intercept

$-1.18(.43)^{* *}$

Within-person variables

Coworker Incivility

$.03 *(.01)$

Residual variance at within-level

$1.00(.00)^{* * *}$

Between-person covariates

Age

$-.97^{* * *}(.21)$

Gender

$.66^{* * *}(.18)$

Job Tenure

$-.07(.12)$

Organizational Tenure

$-.08(.12)$

Residual variance at between-level

$.143(.21)$

Note. Regression coefficients were standardized estimates from the Mplus output corresponding to the multilevel model. Standard errors were reported in parentheses.

$* p<.05, * * p<.01 * * * p<.001$. 
NURSES CAN'T EVEN

Table 3.

Multilevel Estimates for Model 2a Predicting Procrastination

Procrastination

Intercept

1.93(1.13)

Within-person variables

PA downshift-NA upshift

$.01(.13)$

PA upshift-NA downshift

$.07(.17)$

PA upshift-NA upshift

$.21^{* * *}(.06)$

PA downshift—NA downshift

$-.07(.11)$

Residual variance at within-level

$.95^{* * *}(.04)$

Between-person covariates

Age

$.62(.46)$

Gender

Job Tenure

$-1.03 *(.45)$

Organizational Tenure

$.54 *(.27)$

Residual variance at between-level

$.44(.37)$

Note. Regression coefficients were standardized estimates from the Mplus output corresponding to the multilevel model. Standard errors were reported in parentheses.

${ }^{*} p<.05,{ }^{* *} p<.01 * * * p<.001$. 
NURSES CAN'T EVEN

Table 4.

Multilevel Estimates for Model $2 b$ Predicting Residual Systolic Blood Pressure

Blood Pressure

Intercept

$-.22(2.26)$

Within-person variables

PA downshift-NA upshift

$.21 *(.10)$

PA upshift-NA downshift

$-.04(.07)$

PA upshift-NA upshift

$-.03(.15)$

PA downshift-NA downshift

$.02(.13)$

Caffeine T1

$.41^{* * *}(.13)$

Medicine T1

$-.17(.22)$

Caffeine T2

$.27^{*}(.13)$

Residual variance at within-level

$.63^{* * *}(.12)$

Between-person covariates

Age

$.59(.56)$

Gender

$-.52(.51)$

Job Tenure

$.09(.87)$

Organizational Tenure

$-.49(.54)$

Residual variance at between-level

$.62(.51)$

Note. Regression coefficients were standardized estimates from the Mplus output corresponding to the multilevel model. Standard errors were reported in parentheses. ${ }^{*} p<.05,{ }^{* *} p<.01 * * * * \leq .001$. 
NURSES CAN'T EVEN

Table 5.

Model Estimates of the Indirect Effect

\begin{tabular}{lcccc}
\hline Hypothesized Models & $\beta$ & $S E$ & $p$ & $95 \%$ CI \\
Coworker Incivility $\rightarrow$ PA downshift-NA upshift $\rightarrow$ & .000 & .004 & .989 & {$[-.008$,} \\
$\begin{array}{l}\text { Procrastination } \\
\begin{array}{l}\text { Coworker Incivility } \rightarrow \text { PA downshift—NA upshift } \rightarrow \text { Blood } \\
\text { Pressure }\end{array}\end{array}$ & .014 & .051 & .784 & {$[-.087$,} \\
\hline
\end{tabular}

Table 6.

Multilevel Estimates for Model 4 Moderating Effects of Sleep Quality

PA downshift-NA upshift

Intercept

$-1.26^{* * *}(.32)$

Within-person variables

Coworker Incivility

$.19(.13)$

Sleep Quality

$-.00(.07)$

Coworker Incivility X Sleep Quality

$-.01(.12)$

PA upshift-NA downshift

$-.12 *(.05)$

PA upshift—NA upshift

$-.36^{* * *}(.10)$

PA downshift-NA downshift

$-.19 * * *(.04)$

Residual variance at within-level

$.89 * * *(.06)$

Between-person covariates

Age

$-1.00^{* * *}(.22)$

Gender

$.723^{* * *}(.18)$

Job Tenure

$.02(.11)$

Organizational Tenure

$-.20(.12)$

Residual variance at between-level

$.08(.16)$

Note. Regression coefficients were standardized estimates from the Mplus output corresponding to the multilevel model. Standard errors were reported in parentheses.

${ }^{*} p<.05,{ }^{* *} p<.01{ }^{* * *} p<.001$. 
NURSES CAN'T EVEN

Table 7.

Research design and measurement time intervals for all focal variables and relevant control variables

\begin{tabular}{lccc}
\hline \multicolumn{1}{c}{ Variables } & $\begin{array}{c}\text { Time 1 (beginning of } \\
\text { shift) }\end{array}$ & $\begin{array}{c}\text { Time 2 (middle of } \\
\text { shift) }\end{array}$ & Time 3 (end of shift) \\
Coworker incivility & & $\mathrm{X}$ & \\
Positive Affect & $\mathrm{X}$ & $\mathrm{X}$ & \\
Negative Affect & $\mathrm{X}$ & $\mathrm{X}$ & $\mathrm{X}$ \\
Procrastination & & $\mathrm{X}$ & \\
Systolic Blood Pressure & $\mathrm{X}$ & & \\
(Previous night's) Sleep & $\mathrm{X}$ & & \\
Quality & & $\mathrm{X}$ & \\
Caffeine intake & $\mathrm{X}$ & & \\
Medicine & $\mathrm{X}$ & & \\
\hline
\end{tabular}

Note. All variables were measured on level 1 or within-person at the day level.

Affective shift patterns were calculated using the positive and negative affect data from both time points. 
Table 8

Missing data for shifts and time points

\begin{tabular}{|c|c|c|c|c|c|c|c|}
\hline Participant & $\begin{array}{c}\text { \# of } \\
\text { shifts }\end{array}$ & $\begin{array}{c}\text { Missing } \\
\text { T1 }\end{array}$ & $\begin{array}{c}\text { Missing } \\
\text { BP1 }\end{array}$ & $\begin{array}{c}\text { Missing } \\
\text { T2 }\end{array}$ & $\begin{array}{c}\text { Missing } \\
\text { BP2 }\end{array}$ & $\begin{array}{c}\text { Missing } \\
\text { T3 }\end{array}$ & $\begin{array}{c}\text { Missing } \\
\text { BP3 }\end{array}$ \\
\hline 1 & 1 & 0 & 0 & 0 & 0 & 0 & 0 \\
\hline 2 & 5 & 0 & 0 & 4 & 4 & 3 & 3 \\
\hline 3 & 3 & 0 & 0 & 1 & 1 & 1 & 1 \\
\hline 4 & 5 & 0 & 0 & 1 & 2 & 1 & 1 \\
\hline 5 & 8 & 0 & 0 & 3 & 3 & 4 & 4 \\
\hline 6 & 7 & 0 & 0 & 3 & 3 & 2 & 2 \\
\hline 7 & 6 & 0 & 0 & 2 & 2 & 2 & 2 \\
\hline 8 & 6 & 0 & 0 & 1 & 1 & 1 & 1 \\
\hline 9 & 7 & 1 & 1 & 1 & 1 & 1 & 1 \\
\hline 10 & 3 & 0 & 0 & 1 & 1 & 2 & 2 \\
\hline 11 & 7 & 0 & 0 & 0 & 0 & 0 & 0 \\
\hline 12 & 1 & 0 & 0 & 1 & 1 & 0 & 0 \\
\hline 13 & 6 & 0 & 0 & 6 & 6 & 0 & 4 \\
\hline 14 & 1 & 0 & 0 & 0 & 0 & 1 & 1 \\
\hline 15 & 2 & 0 & 0 & 0 & 0 & 0 & 0 \\
\hline 16 & 3 & 0 & 0 & 1 & 1 & 3 & 3 \\
\hline 17 & 6 & 0 & 0 & 0 & 0 & 0 & 0 \\
\hline 18 & 6 & 0 & 0 & 0 & 1 & 0 & 0 \\
\hline 19 & 6 & 0 & 0 & 2 & 2 & 1 & 1 \\
\hline 20 & 13 & 0 & 0 & 2 & 8 & 5 & 6 \\
\hline TOTAL & 102 & 1 & 1 & 29 & 37 & 27 & 32 \\
\hline
\end{tabular}

Note. Missing T1-T3 columns represent survey (scale) data. Missing BP1-BP3 represent surveys that were filled out without blood pressure values. 
Figures

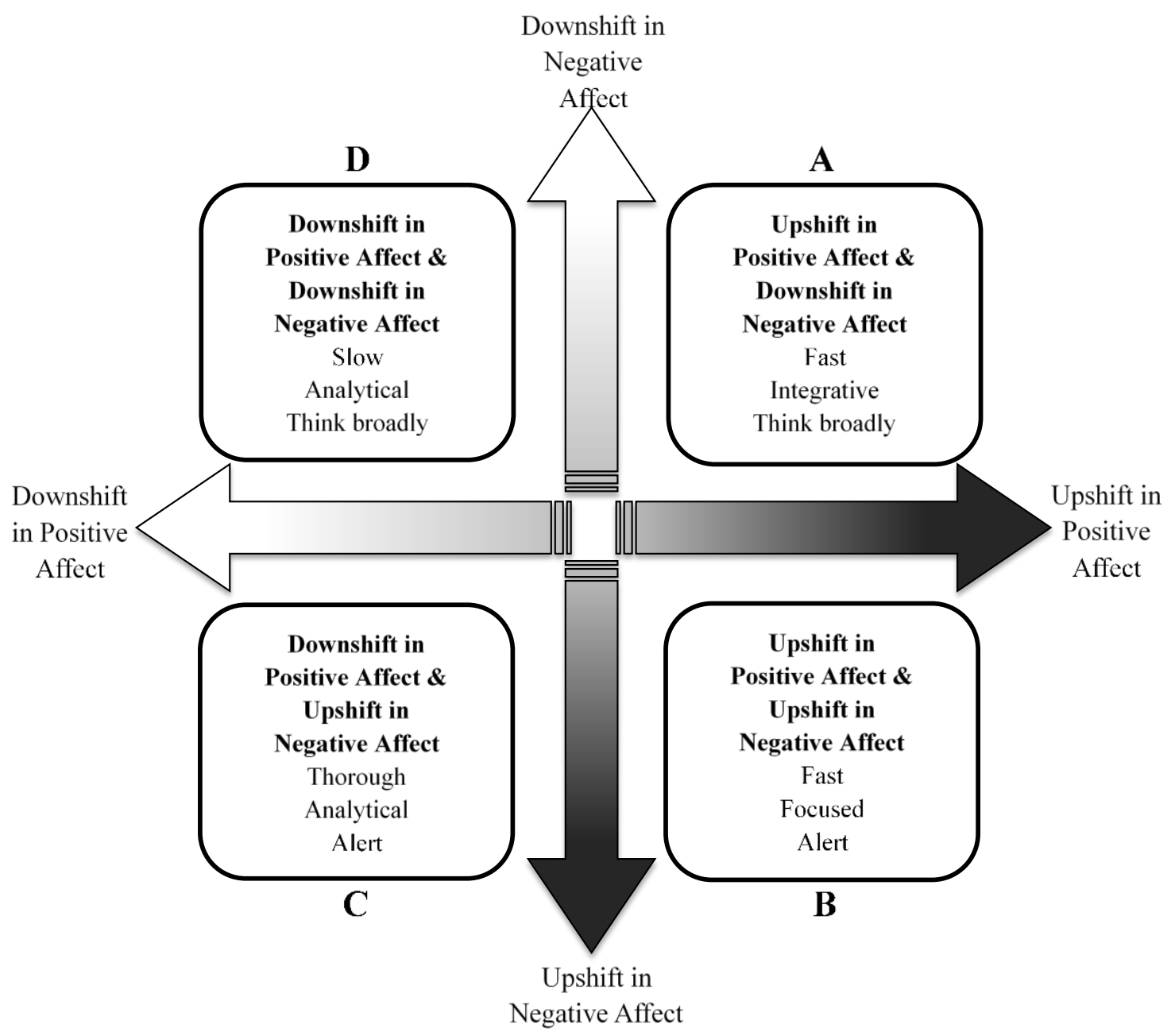

Figure 1. Affective Shift Model (Yang et al., 2016) 


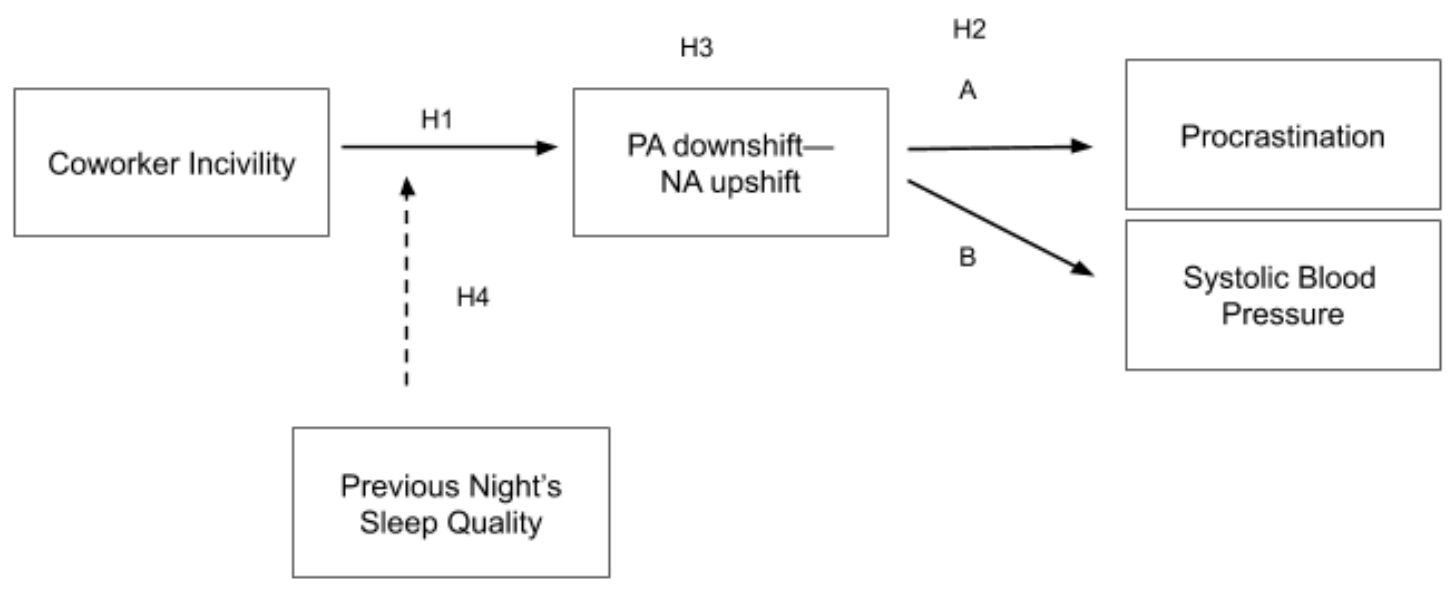

Figure 2. Hypothesized Conceptual Model 


\section{References}

Andersson, L. M., \& Pearson, C. M. (1999). Tit for Tat? The Spiraling Effect of Incivility in the Workplace. Academy of Management Review, 24(3), 452-471. https://doi.org/10.5465/amr.1999.2202131

Beal, D. J. (2015). ESM 2.0: State of the Art and Future Potential of Experience Sampling Methods in Organizational Research. Annual Review of Organizational Psychology and Organizational Behavior, 2(1), 383-407. https://doi.org/10.1146/annurev-orgpsych-032414-111335

Beattie, L., \& Griffin, B. (2014). Day-level fluctuations in stress and engagement in response to workplace incivility: A diary study. Work and Stress, 28(2), 124-142. https://doi.org/10.1080/02678373.2014.898712

Berry, D. T. R., \& Webb, W. B. (1983). State measures and sleep stages. Psychological Reports, 52(3), 807-812. https://doi.org/10.2466/pr0.1983.52.3.807

Bledow, R., Rosing, K., \& Frese, M. (2013). a Dynamic Perspective on Affect and Creativity. ${ }^{\circledR}$ Academy of Management Journal, 56(2), 432-450. https://doi.org/10.5465/ainj.2010.0894

Bledow, R., Schmitt, A., Frese, M., \& Kühnel, J. (2011). The affective shift model of work engagement. Journal of Applied Psychology, 96(6), 1246-1257. https://doi.org/10.1037/a0024532

Bunk, J. A., \& Magley, V. J. (2013). The role of appraisals and emotions in understanding experiences of workplace incivility. Journal of Occupational Health Psychology, 18(1), 87-105. https://doi.org/10.1037/a0030987

Campbell, J. C., Messing, J. T., Kub, J., Agnew, J., Fitzgerald, S., Fowler, B., Sheridan, 
NURSES CAN'T EVEN

D., Lindauer, C., Deaton, J., \& Bolyard, R. (2011). Workplace Violence: prevalence and risk factors in the safe at work study. Journal of Occupational and

Environmental Medicine, 53(1), 82-89.

https://doi.org/10.1097/JOM.0b013e3182028d55

Caza, B. B., \& Cortina, L. M. (2007). From insult to injury: Explaining the impact of incivility. Basic and Applied Social Psychology, 29(4), 335-350.

https://doi.org/10.1080/01973530701665108

Çelik, S. Ş., Çelik, Y., Ağırbaş, İ., \& Uğurluoğlu, Ö. (2007). Verbal and physical abuse against nurses in Turkey. International Nursing Review, 54(4), 359-366. https://doi.org/10.1111/j.1466-7657.2007.00548.x

Chen, W.-C., Sun, Y.-H., Lan, T.-H., \& Chiu, H.-J. (2009). Incidence and Risk Factors of Workplace Violence on Nursing Staffs Caring for Chronic Psychiatric Patients in Taiwan. International Journal of Environmental Research and Public Health, 6(11), 2812-2821. https://doi.org/10.3390/ijerph6112812

Cortina, L. M., Magley, V. J., Williams, J. H., \& Langhout, R. D. (2001). Incivility in the workplace: Incidence and impact. Journal of Occupational Health Psychology, 6(1), 64-80. https://doi.org/10.1037/1076-8998.6.1.64

Demsky, C. A., Fritz, C., Hammer, L. B., \& Black, A. E. (2019). Workplace incivility and employee sleep: The role of rumination and recovery experiences. Journal of Occupational Health Psychology, 24(2), 228-240. https://doi.org/10.1037/ocp0000116

Diefendorff, J. M., Hall, R. J., Lord, R. G., \& Strean, M. L. (2000). Action-state orientation: Construct validity of a revised measure and its relationship to work- 
NURSES CAN'T EVEN

related variables. Journal of Applied Psychology, 85(2), 250-263.

https://doi.org/10.1037/0021-9010.85.2.250

Eatough, E., Shockley, K., \& Yu, P. (2016). A Review of Ambulatory Health Data

Collection Methods for Employee Experience Sampling Research. Applied

Psychology, 65(2), 322-354. https://doi.org/10.1111/apps.12068

Fisher, C. D., \& To, M. L. (2012). Using experience sampling methodology in organizational behavior. Journal of Organizational Behavior, 33(7), 865-877. https://doi.org/10.1002/job.1803

Ganster, D. C., \& Rosen, C. C. (2013). Work Stress and Employee Health: A Multidisciplinary Review. Journal of Management, 39(5), 1085-1122. https://doi.org/10.1177/0149206313475815

Gilbert-Ouimet, M., Trudel, X., Brisson, C., Milot, A., \& Vézina, M. (2014). Adverse effects of psychosocial work factors on blood pressure: Systematic review of studies on demand-control-support and effort-reward imbalance models. Scandinavian Journal of Work, Environment and Health, 40(2), 109-132. https://doi.org/10.5271/sjweh.3390

Giumetti, G. W., Hatfield, A. L., Scisco, J. L., Schroeder, A. N., Muth, E. R., \& Kowalski, R. M. (2013). What a rude E-mail! examining the differential effects of incivility versus support on mood, energy, engagement, and performance in an online context. Journal of Occupational Health Psychology, 18(3), 297-309. https://doi.org/10.1037/a0032851

Hagger, M. S., Wood, C., Stiff, C., \& Chatzisarantis, N. L. D. (2010). Ego depletion and the strength model of self-control: A meta-analysis. Psychological Bulletin, 136(4), 
NURSES CAN'T EVEN

495-525. https://doi.org/10.1037/a0019486

Hershcovis, M. S., \& Barling, J. (2010). Towards a multi-foci approach to workplace aggression: A meta-analytic review of outcomes from different perpetrators. Journal of Organizational Behavior, 31(1), 24-44. https://doi.org/10.1002/job.621

Hutchinson, M., Wilkes, L., Jackson, D., \& Vickers, M. H. (2010). Integrating individual, work group and organizational factors: Testing a multidimensional model of bullying in the nursing workplace. Journal of Nursing Management, 18(2), 173-181. https://doi.org/10.1111/j.1365-2834.2009.01035.x

Ilies, R., Aw, S. S. Y., \& Lim, V. K. G. (2016). A Naturalistic Multilevel Framework for Studying Transient and Chronic Effects of Psychosocial Work Stressors on Employee Health and Well-Being. Applied Psychology, 65(2), 223-258. https://doi.org/10.1111/apps.12069

Johnson, K. A., Partsch, D. J., Rippole, L. L., \& McVey, D. M. (1999). Reliability of self-reported blood pressure measurements. Archives of Internal Medicine, 159(22), 2689-2693. https://doi.org/10.1001/archinte.159.22.2689

Kamchuchat, C., Chongsuvivatwong, V., Oncheunjit, S., Yip, T. W., \& Sangthong, R. (2008). Workplace violence directed at nursing staff at a general hospital in southern Thailand. Journal of Occupational Health, 50(2), 201-207. https://doi.org/10.1539/joh.O7001

Karlin, W. A., Brondolo, E., \& Schwartz, J. (2003). Workplace Social Support and Ambulatory Cardiovascular Activity in New York City Traffic Agents. Psychosomatic Medicine, 65(2), 167-176. https://doi.org/10.1097/01.PSY.0000033122.09203.A3 
NURSES CAN'T EVEN

Kuhl, J. (2000). A Functional-Design Approach to Motivation and Self-Regulation. In Handbook of Self-Regulation (pp. 111-169). Elsevier. https://doi.org/10.1016/B978012109890-2/50034-2

Kuhl, J., Kazén, M., \& Koole, S. L. (2006). Putting self-regulation theory into practice: A user's manual. Applied Psychology, 55(3), 408-418. https://doi.org/10.1111/j.14640597.2006.00260.x

Kuhl, J., \& Koole, S. L. (2008). The functional architecture of approach and avoidance motivation. Handbook of Approach and Avoidance Motivation, 13298, 535-553. https://doi.org/10.4324/9780203888148.ch32

Kühnel, J., Bledow, R., \& Feuerhahn, N. (2016). When do you procrastinate? Sleep quality and social sleep lag jointly predict self-regulatory failure at work. Journal of Organizational Behavior, 37(7), 983-1002. https://doi.org/10.1002/job.2084

Landsbergis, P. A., Dobson, M., Koutsouras, G., \& Schnall, P. (2013). Job strain and ambulatory blood pressure: A meta-analysis and systematic review. American Journal of Public Health, 103(3), 61-71. https://doi.org/10.2105/AJPH.2012.301153

Leiter, M. P., \& Day, A. (2013). Straightforward incivility scale manual. Technical DocUment: Centre for Organizational Research, Acadia University.

Leiter, M. P., Day, A., \& Price, L. (2015). Attachment styles at work: Measurement, collegial relationships, and burnout. Burnout Research, 2(1), 25-35. https://doi.org/10.1016/j.burn.2015.02.003

Leiter, M. P., Laschinger, H. K. S., Day, A., \& Oore, D. G. (2011). The impact of civility interventions on employee social behavior, distress, and attitudes. Journal of Applied Psychology, 96(6), 1258-1274. https://doi.org/10.1037/a0024442 
Lewis, P. S., \& Malecha, A. (2011). The impact of workplace incivility on the work environment, manager skill, and productivity. Journal of Nursing Administration, 41(1), 41-47. https://doi.org/10.1097/NNA.0b013e3182002a4c

McEwen, B. S. (1998). Stress, Adaptation, and Disease: Allostasis and Allostatic Load. Annals of the New York Academy of Sciences, 840(1), 33-44. https://doi.org/10.1111/j.1749-6632.1998.tb09546.x

Miner, K. N., Settles, I. H., Pratt-Hyatt, J. S., \& Brady, C. C. (2012). Experiencing Incivility in Organizations: The Buffering Effects of Emotional and Organizational Support. Journal of Applied Social Psychology, 42(2), 340-372. https://doi.org/10.1111/j.1559-1816.2011.00891.x

Norlander, T., Johansson, Å., \& Bood, S. Å. (2005). The affective personality: Its relation to quality of sleep, well-being and stress. Social Behavior and Personality, 33(7), 709-722. https://doi.org/10.2224/sbp.2005.33.7.709

Oyeleye, O., Hanson, P., O’Connor, N., \& Dunn, D. (2013). Relationship of workplace incivility, stress, and burnout on nurses' turnover intentions and psychological empowerment. Journal of Nursing Administration, 43(10), 536-542. https://doi.org/10.1097/NNA.0b013e3182a3e8c9

Pai, H.-C., \& Lee, S. (2011). Risk factors for workplace violence in clinical registered nurses in Taiwan. Journal of Clinical Nursing, 20(9-10), 1405-1412. https://doi.org/10.1111/j.1365-2702.2010.03650.x

Palmer, C. A., \& Alfano, C. A. (2017). Sleep and emotion regulation: An organizing, integrative review. Sleep Medicine Reviews, 31, 6-16. https://doi.org/10.1016/J.SMRV.2015.12.006 
Park, Y. A., Fritz, C., \& Jex, S. M. (2018). Daily Cyber Incivility and Distress: The Moderating Roles of Resources at Work and Home. Journal of Management, 44(7), 2535-2557. https://doi.org/10.1177/0149206315576796

Pearson, C. M., \& Porath, C. L. (2005). On the nature, consequences and remedies of workplace incivility: No time for "nice"? Think again. Academy of Management Perspectives, 19(1), 7-18. https://doi.org/10.5465/AME.2005.15841946

Phillips, J. M., Stalter, A. M., Winegardner, S., Wiggs, C., \& Jauch, A. (2018). Systems thinking and incivility in nursing practice: An integrative review. Nursing Forum, 53(3), 286-298. https://doi.org/10.1111/nuf.12250

Podsakoff, P. M., MacKenzie, S. B., Lee, J.-Y., \& Podsakoff, N. P. (2003). Common method biases in behavioral research: A critical review of the literature and recommended remedies. Journal of Applied Psychology, 88(5), 879-903. https://doi.org/10.1037/0021-9010.88.5.879

Porath, C. L., \& Pearson, C. M. (2012). Emotional and behavioral responses to workplace incivility and the impact of hierarchical status. Journal of Applied Social Psychology, 42(SUPPL. 1). https://doi.org/10.1111/j.1559-1816.2012.01020.x

Rogelberg, S., \& Stanton, J. (2007). Introduction: Understanding and dealing with organizational survey nonresponse. http://journals.sagepub.com/doi/abs/10.1177/1094428106294693

Rosen, C. C., Gabriel, A. S., Koopman, J., \& Johnson, R. E. (2016). Who strikes back? A daily investigation of when and why incivility begets incivility. Journal of Applied Psychology, 101(11), 1620-1634. https://doi.org/10.1037/apl0000140

Rothbard, N. P., \& Wilk, S. L. (2011). Waking up on the right side of the bed: The 
NURSES CAN'T EVEN

influence of mood on work attitudes and performance. Academy of Management Journal, 54(5), 959-980. https://doi.org/10.5465/amj.2007.0056

Sakurai, K. (2011). Counterproductive work behaviors: The moderating role of supervisor. Unpublished Manuscript, May.

Schilpzand, P., De Pater, I. E., \& Erez, A. (2016). Workplace incivility: A review of the literature and agenda for future research. Journal of Organizational Behavior, 37(October), S57-S88. https://doi.org/10.1002/job.1976

Scott, B. A., \& Judge, T. A. (2006). Insomnia, Emotions, and Job Satisfaction: A Multilevel Study. Journal of Management, 32(5), 622-645. https://doi.org/10.1177/0149206306289762

Shieh, G. (2009). Detecting Interaction Effects in Moderated Multiple Regression With Continuous Variables Power and Sample Size Considerations. Organizational Research Methods, 12, 510-528. https://doi.org/10.1177/1094428108320370

Shockley, K. M., \& Allen, T. D. (2013). Episodic work-family conflict, cardiovascular indicators, and social support: An experience sampling approach. Journal of Occupational Health Psychology, 18(3), 262-275. https://doi.org/10.1037/a0033137

Sirois, F. M., \& Giguère, B. (2018). Giving in when feeling less good: Procrastination, action control, and social temptations. British Journal of Social Psychology, 57(2), 404-427. https://doi.org/10.1111/bjso.12243

Smith, J. G., Morin, K. H., \& Lake, E. T. (2018). Association of the nurse work environment with nurse incivility in hospitals. Journal of Nursing Management, 26(2), 219-226. https://doi.org/10.1111/jonm.12537

Smith, T. W., Birmingham, W., \& Uchino, B. N. (2012). Evaluative threat and 
NURSES CAN'T EVEN

ambulatory blood pressure: Cardiovascular effects of social stress in daily experience. Health Psychology, 31(6), 763-766. https://doi.org/10.1037/a0026947

Spence Laschinger, H. K., Leiter, M., Day, A., \& Gilin, D. (2009). Workplace empowerment, incivility, and burnout: Impact on staff nurse recruitment and retention outcomes. Journal of Nursing Management, 17(3), 302-311. https://doi.org/10.1111/j.1365-2834.2009.00999.x

Stanton, J. M., Balzer, W. K., Smith, P. C., Parra, L. F., \& Ironson, G. (2001). A general measure of work stress: The stress in general scale. Educational and Psychological Measurement, 61(5), 866-888. https://doi.org/10.1177/00131640121971455

Thompson, E. R. (2007). Development and Validation of an Internationally Reliable Short-Form of the Positive and Negative Affect Schedule (PANAS). Journal of Cross-Cultural Psychology, 38(2), 227-242. https://doi.org/10.1177/0022022106297301

Tice, D. M., Bratslavsky, E., \& Baumeister, R. F. (2001). Emotional distress regulation takes precedence over impulse control: If you feel bad, do it! Journal of Personality and Social Psychology, 80(1), 53-67. https://doi.org/10.1037/0022-3514.80.1.53

Tuckman, B. W. (1991). The Development and Concurrent Validity of the Procrastination Scale. Educational and Psychological Measurement, 51(2), 473480. https://doi.org/10.1177/0013164491512022

van den Hoogen, P. C. W., Feskens, E. J. M., Nagelkerke, N. J. D., Menotti, A., Nissinen, A., \& Kromhout, D. (2000). The Relation between Blood Pressure and Mortality Due to Coronary Heart Disease among Men in Different Parts of the World. New England Journal of Medicine, 342(1), 1-8. 
NURSES CAN'T EVEN

https://doi.org/10.1056/NEJM200001063420101

Veit, R., Brody, S., \& Rau, H. (1997). Four-year stability of cardiovascular reactivity to psychological stress. Journal of Behavioral Medicine, 20(5), 447-460. https://doi.org/10.1023/A:1025599415918

Verasari, M., \& Hamzah, H. (2019). The Effect of Experienced Incivility From Supervisor and Coworkers Towards Instigated Incivility in Daily Level Among Nurses. International Journal for Educational and Vocational Studies, 1(4), 359363. https://doi.org/10.29103/ijevs.v1i4.1781

Watson, D., Clark, L., \& Tellegan, A. (1988). Development and validation of brief measures of positive and negative affect: The PANAS scales. Journal of Personality and Social Psychology, 54(6), 1063-1070. http://doi.apa.org/journals/psp/54/6/1063.html

Wong, J. H. K., \& Kelloway, E. K. (2016). What happens at work stays at work? Workplace supervisory social interactions and blood pressure outcomes. Journal of Occupational Health Psychology, 21(2), 133-141. https://doi.org/10.1037/a0039900

Yang, L.-Q., \& Caughlin, D. E. (2017). Aggression-preventive supervisor behavior: Implications for workplace climate and employee outcomes. Journal of Occupational Health Psychology, 22(1), 1-18. https://doi.org/10.1037/a0040148

Yang, L.-Q., Johnson, R. E., Bauer, J., Groer, M. W., \& Salomon, K. (2014).

Physiological mechanisms that underlie the effects of Interactional unfairness on deviant behavior: The role of cortisol activity. Journal of Applied Psychology, 99(2), 310-321. https://doi.org/10.1037/a0034413

Yang, L.-Q., Simon, L. S., Wang, L., \& Zheng, X. (2016). To branch out or stay focused? 
NURSES CAN'T EVEN

Affective shifts differentially predict organizational citizenship behavior and task performance. Journal of Applied Psychology, 101(6), 831-845.

https://doi.org/10.1037/ap10000088

Yang, L.-Q., Wipfli, B., Cyr, L., Currans, K., \& Wang, L. (2018). How Do Stressed Workers Make Travel Mode Choices That Are Good For Their Health, Safety, and Productivity? https://pdxscholar.library.pdx.edu/trec_reports/153/

Yu, L., Buysse, D. J., Germain, A., Moul, D. E., Stover, A., Dodds, N. E., Johnston, K. L., \& Pilkonis, P. A. (2011). Development of Short Forms from the PROMIS Sleep Disturbance and Sleep-Related Impairment Item Banks NIH Public Access. Behav Sleep Med, 10(1), 6-24. https://doi.org/10.1080/15402002.2012.636266

Zhou, Z. E., Yan, Y., Che, X. X., \& Meier, L. L. (2015). Effect of workplace incivility on end-of-work negative affect: Examining individual and organizational moderators in a daily diary study. Journal of Occupational Health Psychology, 20(1), 117-130. https://doi.org/10.1037/a0038167 
Appendix: All Scales

\section{Survey Measures}

\section{Straightforward Incivility Scale (Leiter \& Day, 2013)}

During the first half of your shift, how often have your peers (vs. supervisors or patients) behaved in the following ways?

1. Ignored you

2. Excluded you

3. Spoke rudely to you.

4. Behaved rudely to you (e.g. gestures, facial expressions, etc.)

5. Behaved without consideration for you

Response Options: (1) Never to (5) Five or more times

\section{Positive And Negative Affect Schedule, PANAS (Thompson, 2007)}

This scale consists of a number of words and phrases that describe feelings and emotions. Please indicate to what extent you feel this way right now.

1. Alert

2. Inspired

3. Determined

4. Attentive

5. Active

6. Ashamed

7. Nervous

8. Afraid

9. Upset

10. Hostile 
NURSES CAN'T EVEN

Response Options: (1) Not at all to (6) Extremely

\section{Shortened Procrastination Scale (Tuckman, 1991)}

To what extent do you agree with these statements?

1. Today, I needlessly delayed finishing work tasks, even when they are important.

2. Today, for a work deadline, I waited till the last minute.

3. Today, I delayed making tough decisions at work.

4. Today, I managed to find an excuse for not doing something at work.

5. Today, I promised myself I would do something at work and then dragged my feet.

6. Today, I got stuck in neutral even though I knew how important it was to get started on something at work.

Response Options: (1) Not at all to (6) Extremely

\section{Patient-Reported Outcomes Measurement Information System (PROMIS ${ }^{\text {TM}) ~ S l e e p ~}$} Disturbance (SD) (Yu et al., 2011)

Please select the answer that best reflects your most recent sleep (NOT including short naps).

1. My sleep was restless.

2. I was satisfied with my sleep.

3. My sleep was refreshing.

4. I had difficulty falling asleep.

5. I had trouble staying asleep. 
NURSES CAN'T EVEN

6. I had trouble sleeping.

7. I got enough sleep.

8. My sleep quality was...

Response Options for \#1-7: (1) Not at all to (5) Very much

Response Options for \#8: (1) Very poor to (5) Very good 